\title{
Links between deep-sea respiration and community dynamics
}

\author{
Henry A. Ruhl, ${ }^{1,4}$ Brian J. Bett, ${ }^{1}$ Sarah J. M. Hughes, ${ }^{2}$ Claudia H. S. Alt,${ }^{2}$ Elizabeth J. Ross, ${ }^{2}$ \\ Richard S. Lampitt, ${ }^{1}$ Corinne A. Pebody, ${ }^{1}$ Kenneth L. Smith, ${ }^{3}$ and David S. M. Billett ${ }^{1}$ \\ ${ }^{1}$ National Oceanography Centre, University of Southampton Waterfront Campus, European Way, Southampton SO14 $3 Z \mathrm{ZH}$ \\ United Kingdom \\ ${ }^{2}$ School of Ocean and Earth Science, University of Southampton, National Oceanography Centre, European Way, \\ Southampton SO143HZ United Kingdom \\ ${ }^{3}$ Monterey Bay Aquarium Research Institute, 7700 Sandholdt Road, Moss Landing, California 95039 USA
}

\begin{abstract}
It has been challenging to establish the mechanisms that link ecosystem functioning to environmental and resource variation, as well as community structure, composition, and compensatory dynamics. A compelling hypothesis of compensatory dynamics, known as "zero-sum" dynamics, is framed in terms of energy resource and demand units, where there is an inverse link between the number of individuals in a community and the mean individual metabolic rate. However, body size energy distributions that are nonuniform suggest a niche advantage at a particular size class, which suggests a limit to which metabolism can explain community structuring. Since 1989, the composition and structure of abyssal seafloor communities in the northeast Pacific and northeast Atlantic have varied interannually with links to climate and resource variation. Here, for the first time, class and mass-specific individual respiration rates were examined along with resource supply and time series of density and biomass data of the dominant abyssal megafauna, echinoderms. Both sites had inverse relationships between density and mean individual metabolic rate. We found fourfold variation in echinoderm respiration over interannual timescales at both sites, which were linked to shifts in species composition and structure. In the northeastern Pacific, the respiration of mobile surface deposit feeding echinoderms was positively linked to climatedriven particulate organic carbon fluxes with a temporal lag of about one year, respiring $\sim 1-$ $6 \%$ of the annual particulate organic carbon flux.
\end{abstract}

Key words: benthic; biogeochemistry; carbon; compensatory dynamics; deep sea; echinoderm; respiration; zero-sum dynamics.

\section{INTRODUCTION}

In recent decades, long-term trends in ocean environmental variables have been identified, including warming, acidification, and productivity (Orr et al. 2005, Gehlen et al. 2007, Frölicher et al. 2009, Keeling et al. 2010, Steinacher et al. 2010). Understanding the relationships between environmental drivers and ecological variation over time in the deep sea comes from relatively few records (Glover et al. 2010, Ruhl et al. 2011). Links have been found between climate-driven shifts in sea surface productivity, sinking particulate organic carbon (POC) flux, and deep-sea biomass, density, and community composition over periods as short as months (Ruhl et al. 2008, Smith et al. 2008, Billett et al. 2010, Moeseneder et al. 2012). Nevertheless, improving estimates of how the structural and functional attributes of benthic deep-sea systems will respond to a changing climate require improved understanding of ecological mechanisms and biogeochemical processes.

Manuscript received 10 April 2013; revised 5 September 2013; accepted 5 November 2013. Corresponding Editor: M. H. Carr.

${ }^{4}$ E-mail: h.ruhl@noc.ac.uk
Assemblages of benthic megafauna at Station M (Sta. $\mathrm{M})$ in the northeast Pacific and the Porcupine Abyssal Plain (PAP) in the northeast Atlantic have undergone substantial changes in their abundance and composition at the seafloor since 1989 (Billett et al. 2010, Ruhl 2008). Echinoderms dominate the mobile benthic megafauna (i.e., for marine benthic fauna, this includes those with mass of $\sim 1 \mathrm{~g}$ wet mass or more) at these sites (Billett et al. 2010, Ruhl 2008). The marked dynamics provided an opportunity to investigate mechanisms that may relate to changes in composition and structure, and their connection to biogeochemical processes and ecosystem functions.

One of the key sets of mechanisms that are thought to control community dynamics are those relating to compensatory dynamics and resource limitation. The hypothesis of "compensatory dynamics" posits that when resource levels are fixed, total abundance is constant, and increases in abundance of one taxon are compensated for by reductions in another (Hubbell 2001, Ernest and Brown 2001, Houlahan et al. 2007). In real systems, however, evidence for such interspecific compensatory dynamics of abundances is limited. Specifically, little evidence exists for $>50 \%$ negative covariance of abundance between various taxa expected 
from random interactions (e.g., Houlahan et al. 2007). Indeed, interspecific compensation can occur without negative density covariance, such as when all species might increase in abundance in response to a resource increase, but change their relative rank dominance because of differential resource use, or when taxa of different size change abundance relative to each other where there is an inverse relationship between density and mean individual metabolic rate during different parts of a time series.

"Zero-sum" dynamics posits a compensation hypothesis that directly examines energetic compensation (e.g., Ernest et al. 2008, 2009). Respiration is a key measure to frame ecological variations in a currency that accounts for the fact that resource use rates are dependent, in part, on body size, where larger fauna have lower massspecific respiration rates than smaller fauna. A testable hypothesis of zero-sum theory is that, given a fixed resource input and constant temperature, the total number of individuals $(N)$ in a community is inversely related to the mean individual metabolic rate $(B)$, where $N \propto B^{-1}$ (Fig. 1). Such an inverse relationship was observed in, for example, tropical forest data (Ernest et al. 2009). It follows from that hypothesis that, if resources increase (i.e., $[R] / B \propto N$, where $R$ is available resource), that would allow an increase in density at a given mean individual respiration rate (or any combination of increased density and mean individual metabolic rate that equates to the increased resource). Fluctuations in resources over time could thus manifest as residuals from a best fit relationship of the whole time period where positive residuals relate to increased resource levels (Fig. 1).

In a related thread of ecological theory, rank abundance distributions (RADs) are believed to be an indicator of biodiversity that describes the abundance and dominance of each taxa relative to the others and is indicative of resource use by each rank (Motomura 1932, MacArthur 1957, Whittaker 1965, Sugihara et al. 2003, Thibault et al. 2004). Another consequence of zero-sum dynamics is that, as communities shifted to lower mean individual respiration rates (more smaller individuals), there would tend to be an increase in relative dominance of the smaller individuals and decrease in evenness (Fig. 1). Thus, examination of rank energy demand distributions provides a more direct measure of resource partitioning than abundance measures by also accounting for such allometric scaling.

Substantial challenges remain in reconciling such strictly size-based theories with niche theories that necessitate other life history traits such as food selectivity differences at a given body size. A strictly energetic view of community structuring suggests a uniform relationship between mean individual size and the resources used at each size class. However, multimodal distributions have been found in body size energy distributions, suggesting a limit to which body size can explain community structuring (e.g., Ernest
2005), whereby some specific sizes may have niche advantages in a given habitat.

How variation in the structure of echinoderm assemblages influences their net functional role is poorly understood. One of the key ecosystem functions of benthic fauna is to remineralize POC that sinks to the seafloor (food supply) through the processes of respiration and nutrient regeneration. Dynamics of sediment community oxygen consumption (SCOC) is an indicator of the temporal variation in food demand. However, because of the nature of the respiration chambers typically used for studying SCOC, the respiratory demands of megafauna assemblages previously have not been systematically measured in examining food supply and demand.

Here we present the first assessment of long-term variation in the respiration of echinoderm assemblages from deep-sea habitats to provide insights into the mechanisms driving their structure, dynamics, and biogeochemical function. We examined if total respiration of the echinoderm assemblage is correlated with indicators of community composition and structure (CCS). We tested the following predictions of related hypotheses of compensatory dynamics (CD), zero-sum dynamics (ZSD), and multimodal distribution (MMD) in explaining patterns of assemblage structure, dynamics, and functional role: (1) CD, with no long-term trend in food (resource) levels over time, the sign of covariance between pairs of taxon-specific respiration is, on average, more negative than positive among all pairwise combinations; (2) $\mathrm{ZSD}_{1}$, mean individual respiration rate is inversely related to total density, while mean individual respiration rate is positively related to evenness of the echinoderm assemblage; (3) $\mathrm{ZSD}_{2}$, net respiration of the echinoderm assemblage is positively correlated with temporal variation in food supply; (4) $\mathrm{ZSD}_{3}$, residuals in a regression between mean individual respiration rate and total echinoderm density are positively related to resource availability; and (5) MMD, multimodal distributions are present in distributions of energy use across body sizes.

The assemblage was also quantified in terms of food supply and demand, feeding behavior, and the contribution to remineralization of organic carbon on the deep seafloor.

\section{Methods}

This study combined data from several previously published studies, including data from benthic trawling, analyses of feeding guilds, photographic transects of the seafloor, relationships between individual body size and respiration rates, and POC flux data from in situ sediment trap measurements. We calculated respiratory demand of the echinoderm assemblage for the two abyssal echinoderm communities by multiplying mass- and class-specific respiration rates by mean individual biomass and observed density (individuals per unit area) for each taxon during each observation 
time. We have built on a body of work that has examined relationships between individual taxa, their body size, and their respiration rates to make initial estimations of respiration for larger fauna at the seafloor (Smith 1983, Piepenburg and Schmid 1996, Ambrose et al. 2001, Rowe et al. 2008). The relationships between individual size and respiration were determined for each echinoderm class based on a meta-analysis of all available in situ respiration measurements of echinoderms (Hughes et al. 2011), which covered a range of depths to $>4000 \mathrm{~m}$ depth. We applied a temperature correction for each site, modifying the equations presented in Hughes et al. (2011) so that the PAP temperature correction was set to $2.6^{\circ} \mathrm{C}$ and Sta. M to $1.5^{\circ} \mathrm{C}$, the measured ambient temperatures at each site. The mass-specific respiration rate equations take the following form: individual respiration rate $=a M^{b}$, where $M$ is individual wet mass, $a$ is the class specific $y$ intercept, and $b$ is the related exponent.

\section{Megafauna sampling}

Methods varied according to the specific assemblage examined. Camera sled tows were conducted at Station $\mathrm{M}$, which is located offshore of the California coastline in the northeastern Pacific at $34^{\circ} 50^{\prime} \mathrm{N}, 123^{\circ} 00^{\prime} \mathrm{W}$, at $\sim 4100 \mathrm{~m}$ depth. Faunal density and body size estimates were determined using photogrammetric techniques on towed camera sled images. The camera was positioned $\sim 82 \mathrm{~cm}$ above the seafloor and operated to create a roughly continuous set of seafloor images. Here we use a standard definition of megafauna: Those fauna identifiable in these seafloor images (typically $\geq 1 \mathrm{~cm}$ in size, sensu Grassle et al. 1975). The top 10 dominant mobile organisms were enumerated including the Holothuroids Elpidia sp., Peniagone vitrea, P. diaphana, Scotoplanes globosa, Oneirophanta mutabilis, Psychropotes longicauda, Abyssocucumis abyssorum, and Synallactes sp., the echinoid Echinocrepis rostata, and the Ophiuroidea, all of which are echinoderms. Echinoderms make up $>99 \%$ of the mobile individuals observed during the surveys (see Ruhl 2007 for more quantitative details). The species-specific density and body size data captured from the images was combined with length to wet mass conversions to calculate biomass. The length to mass conversions originated from PAP samples using the same species or closest congener in terms of body shape.

Benthic trawling was conducted at the Porcupine Abyssal Plain in the vicinity of $48^{\circ} 50^{\prime} \mathrm{N}, 16^{\circ} 30^{\prime} \mathrm{W}$ in the northeastern Atlantic at a depth of $\sim 4850 \mathrm{~m}$. Here, megafauna are those caught in a semi-balloon otter trawl system with an $8.6 \mathrm{~m}$ opening and $13-\mathrm{mm}$ stretch mesh liner in the cod end (Billett et al. 2001, Merrett and Marshall 1981). This system was typically trawled at $\sim 0.75 \mathrm{~m} / \mathrm{s}$ over the seafloor. Density and biomass data from multiple trawls during a single cruise were averaged to create monthly values. At this site, we only examined the data for the echinoderms, which made up

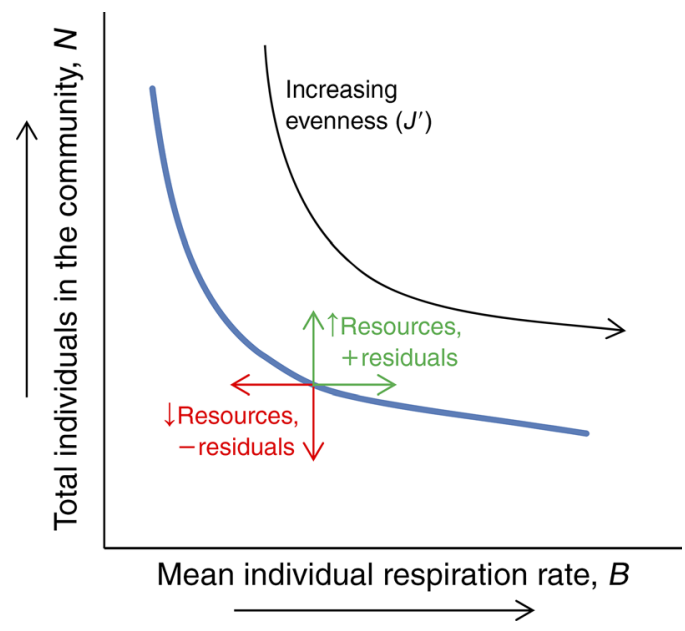

FIG. 1. Conceptual model illustrating the relationships between mean individual respiration rates and total density (blue line), as well as Pielou's evenness index ( $J^{\prime}$, black line) with arrows indicating increases in variable quantity. Thus, this theoretical formulation, including residuals, allows for analysis of data from a temporally dynamic study area.

about $\sim 95 \%$ of the total trawled biomass (see Billett et al. 2010 for more quantitative details). We assigned the echinoderm taxa into feeding guilds based on results from a previous study that examined relative isotope quantities in tissues to establish the trophic position among a large proportion of the fauna collected in PAP trawls (Iken et al. 2001). The guilds were delineated as surface deposit feeders (SDF), subsurface deposit feeders (SSDF), suspension feeders (SF), and predators/scavengers $(\mathrm{P} / \mathrm{S})$. Here too, the fauna were dominated by Holothuroidea, including Amperima rosea, $O$. mutabilis, Ellipinion molle, Ps. longicauda, P. diaphana (all SDFs), and Pseudostichopus spp. (SSDF), as well as Asteroidea, including Hyphalaster inermis (SSDF) and Dytaster grandis grandis $(\mathrm{P} / \mathrm{S})$, Ophiuroidea (SDF), Echinodea (SDF), and Crinoidea (SF).

It is important to note key differences in the methods for density and biomass data for PAP and Station M. PAP results were based on trawl samples, whereas Sta. $M$ were determined photographically. The Sta. M wet mass biomass was estimated from taxon-specific relationships for length to mass, and only the top 10 most abundant mobile epibenthic megafauna were examined. PAP data quantified four echinoderm feeding guilds, whereas Sta. M photographic data only quantified animals feeding at the sediment surface. Thus, at Sta. M, obscured subsurface deposit feeders are left out of any fauna/function calculations. The trawl used at PAP substantially under-samples the echinoderms, with greater under-sampling likely at smaller body sizes, but can reproduce variation in key fauna (Bett et al. 2001). For that reason, only relative variation is considered in conclusions for PAP, rather than the specific values. 


\section{Community indicators}

In order to examine relationships between energetic, biogeochemical, and community variation, we used monthly records to derive a series of uni- and multivariate community descriptors. These descriptors included total echinoderm abundances in terms of density $\left(\mathrm{TA}_{\mathrm{D}}\right)$ and biomass $\left(\mathrm{TA}_{\mathrm{B}}\right)$, as well as total echinoderm respiration (TR). Also included were indices of species composition similarity based on density data $\left(\mathrm{SC}_{\mathrm{D}}\right)$, biomass $\left(\mathrm{SC}_{\mathrm{B}}\right)$, and energetic demand $\left(\mathrm{SC}_{\mathrm{E}}\right)$. We also computed Pielou's evenness $\left(J^{\prime}\right)$ from density data, as well as a series of rank abundance distribution similarity indices based on density $\left(\mathrm{RAD}_{\mathrm{D}}\right)$, biomass $\left(\mathrm{RAD}_{\mathrm{B}}\right)$, and energetic demand $\left(\mathrm{RAD}_{\mathrm{E}}\right)$, where the taxon identity is replaced by rank during each sampling time. For the PAP data set, we also calculated a feeding-guild composition index based on energy use by each guild $\left(\mathrm{FGC}_{\mathrm{E}}\right)$. These indices were created by $\log (x+1)$ transforming the relevant data, and then calculating the Bray-Curtis similarity between all the pairwise sample times. Then, for each data type, we used the multidimensional scaling (MDS) $x$-ordinates plotted over time as indicators of community variation.

\section{Biogeochemical fluxes}

Food supply at both sites was quantified as POC flux using deep-sea sediment trap samples at each site using methods described previously (Baldwin et al. 1998, Lampitt et al. 2010). Each trap is conical in shape and collected material sinking through a baffled entrance with a $0.25-\mathrm{m}^{-2}$ opening. Cups at the bottom of the trap move sequentially to capture samples in time series with regular intervals. These samples are then returned to shore and analyzed for POC content (see Smith et al. 2008 for more quantitative details on Sta. M fluxes). The POC flux data used for Sta. M are a composite of 50 and $600 \mathrm{~m}$ above bottom (mab) trap data, where gaps in the $600 \mathrm{mab}$ record are filled with $50 \mathrm{mab}$ data that has had correction to account for the fact that the 50 mab trap can experience flux of resuspended particulates. This correction was made in the form of a linear regression between using $50 \mathrm{mab}$ as the explanatory variable for the $600 \mathrm{mab}$ data series. POC fluxes at PAP at $3000 \mathrm{~m}$ depth were measured using conical sediment traps (see Lampitt et al. 2010 for more quantitative details on fluxes at PAP). However, POC values for the time period October 2008-July 2011 were estimated from volume flux measurements using an empirically derived linear relationship between the two variables $\left(r^{2}=0.75, P<\right.$ $0.0001)$.

\section{Analytical approach}

Correlations between TR and the community indicators (CCS) were tested using the Spearman's rank correlation test $\left(r_{\mathrm{S}}\right)$, as well as a similarity matrix correlation test with randomization-based significance testing ( $R$; Clarke 1993). Covariances of resource use (respiration) were also calculated between each taxon pair across sampling times (CD). The mean individual respiration rate $\left(\mathrm{TR} / \mathrm{TA}_{\mathrm{D}}\right)$ was tested for correlation to total density and evenness $\left(J^{\prime}\right)$ with an $F$ test used to determine significance for relationships between mean individual respiration rate and total density, and $r_{\mathrm{S}}$ for correlating to evenness $\left(\mathrm{ZSD}_{1}\right)$. Correlation between $\mathrm{TR}$ and POC flux $\left(Z_{2} D_{2}\right)$ was tested via $r_{S}$. POC flux changes were allowed to precede TR in cross correlation, revealing the time lag with a peak in correlation coefficient. The residuals of a least squares power function regression of mean individual respiration rate and total density were then similarly correlated with POC flux via $r_{\mathrm{S}}\left(\mathrm{ZSD}_{3}\right)$. The Kolmogorov-Smirnov Test was used to determine if body size energy distributions were significantly different from a uniform distribution (MMD).

A ratio of food supply to demand was then examined. Here, we considered respiration values in terms of $\mathrm{mg}$ $\mathrm{C} \cdot \mathrm{m}^{-2} \cdot \mathrm{d}^{-1}$ for direct comparison to POC flux units using a respiratory quotient of 0.85 (Smith 1974). The proportion of monthly TR in terms of food (organic carbon) demand $\left(\mathrm{TR}_{\mathrm{C}}\right)$ to POC flux $\left(\mathrm{TR}_{\mathrm{C}}\right.$ :POC flux $)$ provided estimation of the proportion of food input used by the assemblage where $\mathrm{TR}_{\mathrm{C}}$ was compared with the synoptic POC flux, as well as the mean POC flux from the preceding 12 months.

\section{Results}

\section{Station $M$}

The Sta. M time series exhibited variations in TR of about a factor of four (Fig. 2A). The concentration of sampling with time at Sta. M provides a clear indication that variations in respiration of the assemblage can have significant shifts at interannual scales. For example, 1991 and 1994 have significantly different median respiration rates (Mann-Whitney $U$ test, $P=0.02$ ). Respiration (TR) was significantly correlated with both $\mathrm{TA}_{\mathrm{D}}$ and $\mathrm{TA}_{\mathrm{B}}$, with respiration being more highly correlated to $\mathrm{TA}_{\mathrm{B}}$ (CCS hypothesis; Table 1). $\mathrm{TA}_{\mathrm{D}}$ and $\mathrm{TA}_{\mathrm{B}}$ were not directly correlated. In addition, TR was correlated to the species composition descriptors $\mathrm{SC}_{\mathrm{D}}$, $\mathrm{SC}_{\mathrm{B}}$, and $\mathrm{SC}_{\mathrm{E}}$ (Fig. 2, Table 1).

There were also significant correlations between TR and rank abundance indicators $\mathrm{RAD}_{\mathrm{D}}, \mathrm{RAD}_{\mathrm{B}}$, and $\mathrm{RAD}_{\mathrm{E}}$, which were based on density, biomass, and energetic demand respectively (CCS hypothesis; Table 1). Each of these RAD types not only had changes in RAD shape (i.e., relative dominance and evenness), but there were also major shifts in terms of the relative ranks of several taxa (Fig. 3A). Although RAD ${ }_{\mathrm{D}}, \mathrm{RAD}_{\mathrm{B}}$, and $\mathrm{RAD}_{\mathrm{E}}$ variation had similarities, the taxonomic identity of the dominant taxon was frequently not the same from one RAD type to the next and many taxa exhibited substantial changes in relative dominance, in addition to density, biomass, and resource use. For example, near the start of the time series in June 1991, density, biomass, and respiration were each dominated by a different taxon (Fig. 3A, B, and C). There were also 
Sta. M (photographic transect data)
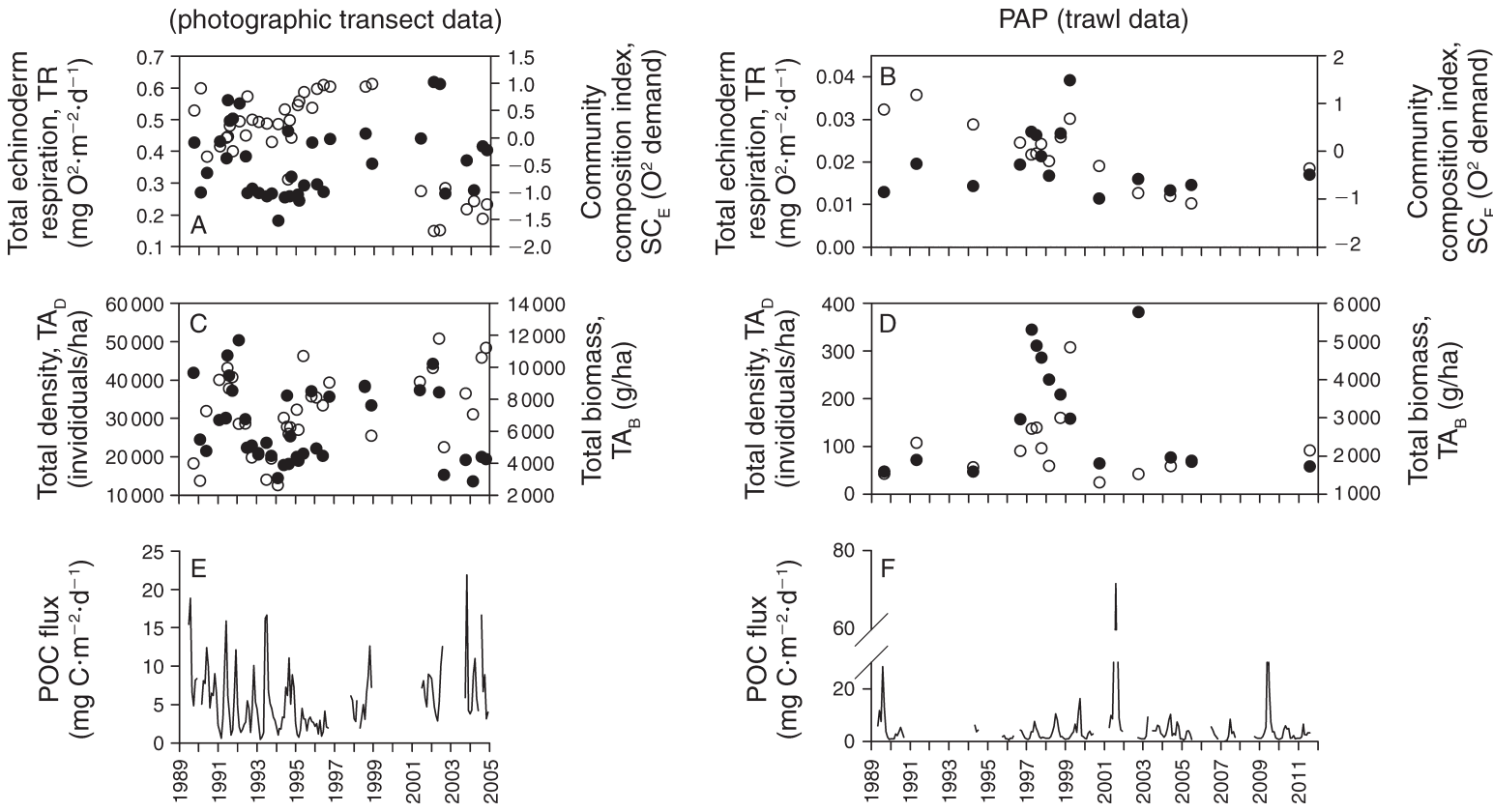

FIG. 2. Time series (by month) of echinoderm megafauna community dynamics for Station M (Sta. M; in the northeast Pacific) and the Porcupine Abyssal Plain (PAP; in the northeast Atlantic) with: (A and B) total respiration of the echnioderm megafauna (solid circles, TR) and an index of echinoderm species composition similarity based on energetic demand (open circles, $\mathrm{SC}_{\mathrm{E}}$ ); and $\left(\mathrm{C}\right.$ and $\mathrm{D}$ ) total density (solid circles, $\mathrm{TA}_{\mathrm{D}}$ ), total biomass (open circles, $\mathrm{TA}_{\mathrm{B}}$ ); (E and F) monthly POC flux to $4050 \mathrm{~m}$ and $3000 \mathrm{~m}$ depth at Sta. M and PAP, respectively. The figure illustrates, in part, that TR varies by up to fourfold for each site, with some synchrony to community composition.

major shifts in rank over time at Sta. M, as shown notably by changes in the holothurian Elpidia spp., the urchin Echinocrepis rostrata, and the brittle stars Ophiuroidea, dominated by Ophiura bathybia. Changes in $\mathrm{SC}_{\mathrm{E}}$ were most closely correlated with density variation of these three taxa $(R=0.58-0.65, P<0.001)$.

The covariance in TR between taxa over time was about one-half negative in sign considering all possible taxon-specific pairwise cases (CD hypothesis). There was a significant negative correlation between mean respiration per individual and total density, an expectation where increases in density are compensated by lower mean individual respiration rates $\left(\mathrm{ZSD}_{1}\right.$ hypothesis; $F=$ 23.2, $P<0.001$; Fig. 4). With no correlation between time and POC flux over the whole time series, there was no monotonic change in resources observed during the study period. Evenness was significantly lower when mean individual respiration rate was lower $\left(\mathrm{ZSD}_{1}\right.$ hypothesis; $r_{\mathrm{S}}=0.48, P=0.002$; Fig. 4). A positive correlation was found between TR and POC flux with a time lag of 13 months $\left(\mathrm{ZSD}_{2}\right.$ hypothesis; $r_{\mathrm{S}}=0.45, P=$ $0.03)$, with an intensity and time lag similar to results for

TABLE 1. Statistical correlation results comparing total echinoderm megafauna respiration (TR; i.e., energy or food demand) from the Station M (Sta. M; in the northeast Pacific; $n=37$ ) photographic data and the Porcupine Abyssal Plain (PAP; in the northeast Atlantic; $n=15$ ) trawl data to various other uni- and multivariate community descriptors.

\begin{tabular}{|c|c|c|c|c|}
\hline \multirow[b]{2}{*}{ Community descriptor } & \multicolumn{2}{|c|}{ Sta. M TR } & \multicolumn{2}{|c|}{ PAP TR } \\
\hline & $r_{\mathrm{S}} / R$ & $P$ & $r_{\mathrm{S}} / R$ & $P$ \\
\hline \multicolumn{5}{|l|}{ Univariate } \\
\hline Total abundance as density, $\mathrm{TA}_{\mathrm{D}}$ & 0.64 & $<0.001$ & 0.61 & 0.02 \\
\hline Total abundance as biomass, $\mathrm{TA}_{\mathrm{B}}$ & 0.82 & $<0.001$ & 0.94 & $<0.001$ \\
\hline \multicolumn{5}{|l|}{ Multivariate } \\
\hline Species composition similarity from density, $\mathrm{SC}_{\mathrm{D}}$ & 0.11 & 0.032 & 0.34 & 0.007 \\
\hline Species composition similarity from biomass, $\mathrm{SC}_{\mathrm{B}}$ & 0.35 & $<0.001$ & 0.20 & 0.07 \\
\hline Species composition similarity from energetic demand, $\mathrm{SC}_{\mathrm{E}}$ & 0.35 & $<0.001$ & 0.42 & 0.02 \\
\hline Rank abundance distribution similarity from density, RAD & 0.23 & $<0.001$ & 0.37 & 0.004 \\
\hline Rank abundance distribution similarity from biomass, RAD $_{B}$ & 0.58 & $<0.001$ & 0.49 & $<0.001$ \\
\hline Rank abundance distribution similarity from energetic demand, $\mathrm{RAD}_{\mathrm{E}}$ & 0.76 & $<0.001$ & 0.78 & $<0.001$ \\
\hline
\end{tabular}

Note: For univariate community descriptors, $r_{\mathrm{S}}$ values are shown, and for multivariate descriptors, $R$ values are shown. 


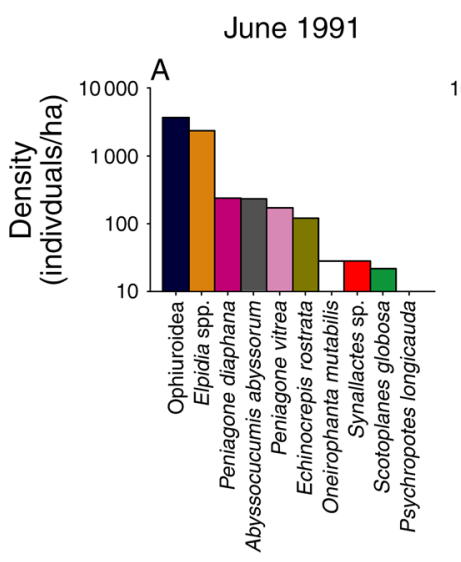

February 1994

August 1998

October 2004
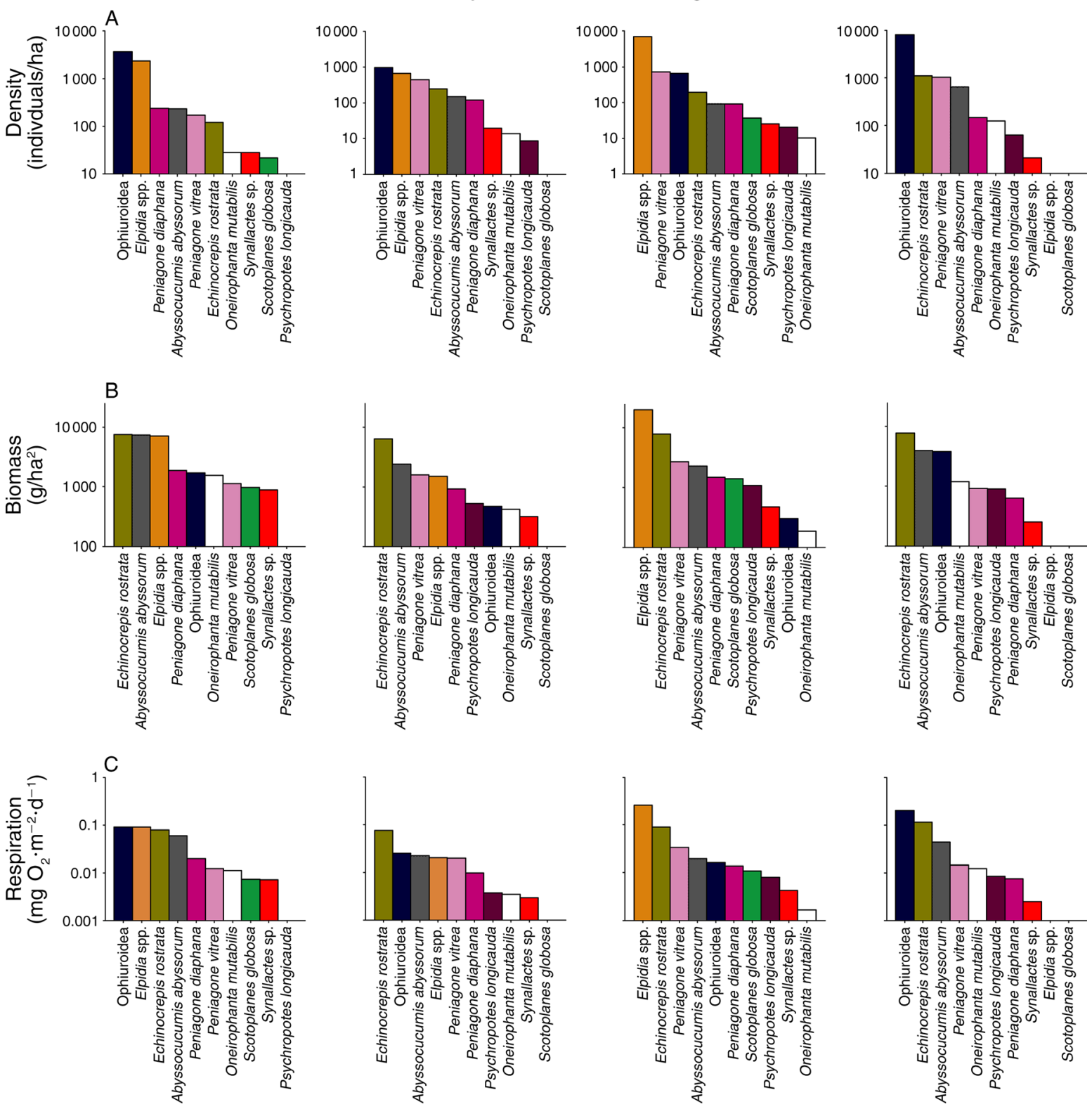

FIG. 3. Rank distribution plots for Sta. M data for selected times during the time series based on (A) density, (B) biomass, and (C) energetic demand (respiration). PAP data are similarly shown in (D) for density, (E) biomass, and (F) energetic demand (respiration). The surface deposit feeders (SDF) are shown with open bars, subsurface deposit feeders (SSDF) are shown with diagonally hatched bars, suspension feeders (SF) have horizontally hatched bars, and predators/scavengers $(\mathrm{P} / \mathrm{S})$ are crosshatched. The figure illustrates differences between density, biomass, and resource use by species, as well as how various taxon rank in these factors at specific times, as well as changes in the shape and magnitude of the rank abundance distributions (RADs).

correlations between $\mathrm{SC}_{\mathrm{D}}$ and $\mathrm{POC}$ flux found previously (Ruhl 2008). The monthly echinoderm assemblage food demand was $\sim 1-6 \%$ of the mean POC flux food supply of the preceding 12 months, and as much as $10 \%$ of the synoptic monthly supply (Fig. 5A). The residuals of the density-mean respiration rate relationship are positively correlated to monthly POC flux to the seafloor with a time lag of 12 months $\left(\mathrm{ZSD}_{2}\right.$ hypothesis; $r_{\mathrm{S}}=$ $0.42, \quad P=0.03$; Fig. 4). When body size energy distributions were examined across these two different parts of the time series, each period showed multimodal distributions (MMD hypothesis; $P<0.001$; Fig. 6).

\section{$P A P$}

Here too we found approximately fourfold variation in TR (Fig. 2B). The TR variation was significantly correlated with $\mathrm{TA}_{\mathrm{D}}, \mathrm{TA}_{\mathrm{B}}, \mathrm{SC}_{\mathrm{D}}$, and $\mathrm{SC}_{\mathrm{E}}$, but not significantly to $\mathrm{SC}_{\mathrm{B}}$ (CCS hypothesis; Table 1). Corre- 
September 1989
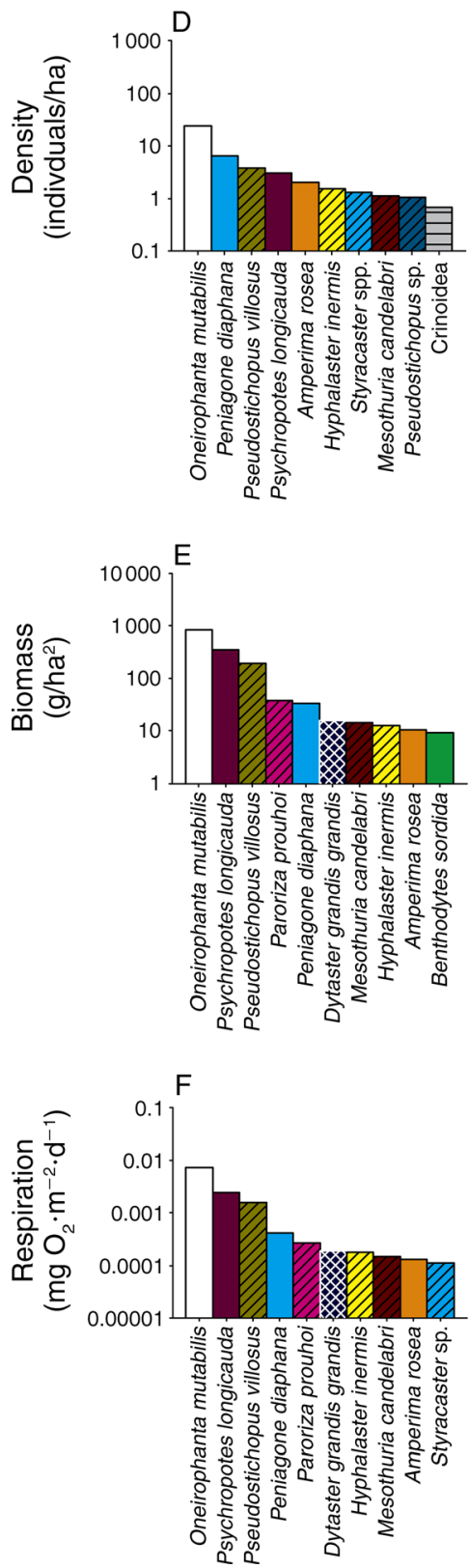

April 1997
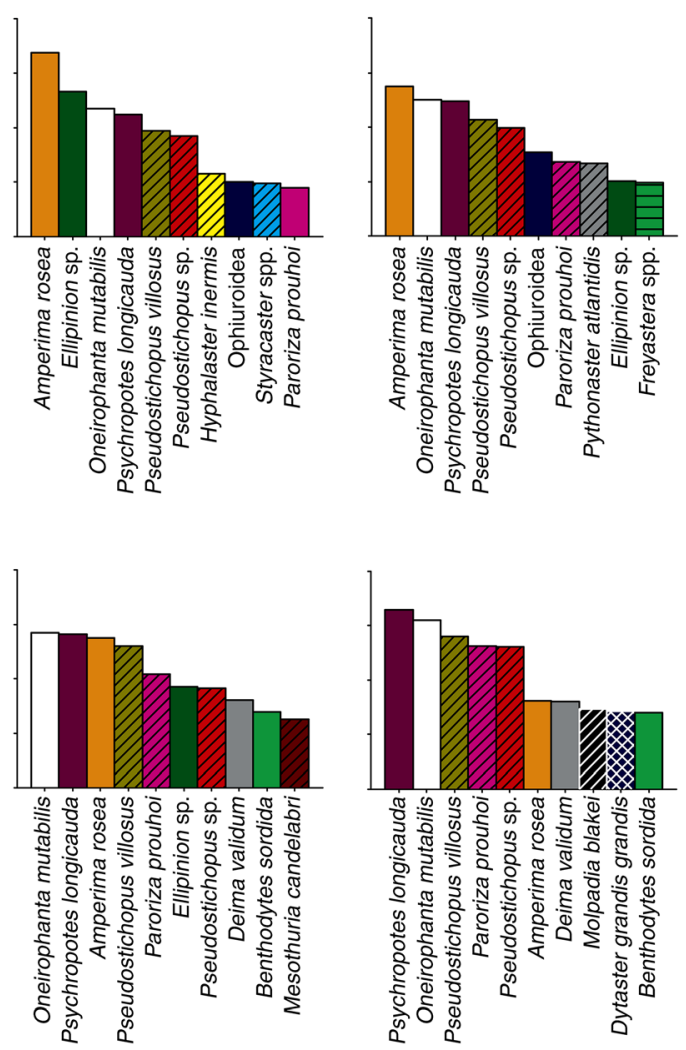

April 1999

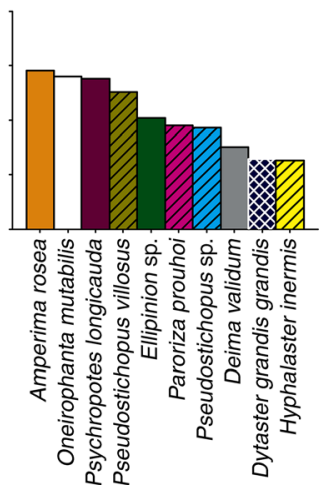

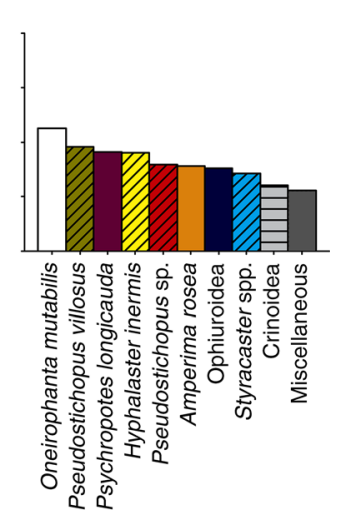

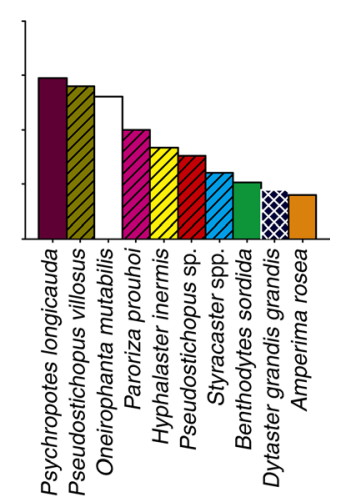

August 2011

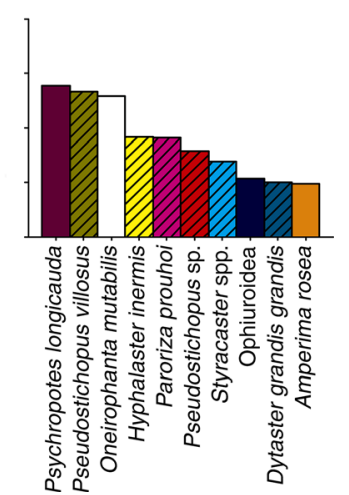

FIG. 3. Continued

lations were also found between TR and RAD descriptors, matching results for Station M. Similarly, $\mathrm{TA}_{\mathrm{D}}$ and $\mathrm{TA}_{\mathrm{B}}$ were not correlated at PAP. The two major peaks in respiration at PAP were associated with a peak in $\mathrm{TA}_{\mathrm{D}}$ in 1997 and $\mathrm{TA}_{\mathrm{B}}$ in 1998 (Fig. 2D).

From the start of the PAP time series, the smaller holothurian $A$. rosea increased in relative density by several orders of magnitude, as well as rank, to become most numerous by April 1997, but A. rosea declined again by the end of the time series (Fig. 3D). The increases in $A$. rosea were accompanied by a reduction in abundance and rank dominance of the holothurian $O$. mutabilis. It is notable that, in April 1997, the dominant species in terms of biomass (O. mutabilis) was not so in terms of resource use. In another example, in April 1999, the most dominant in terms of density ( $A$. rosea) was not so in terms of resource use (Fig. 3D, E, and F). The relatively large holothurian Psychropotes longicauda had relatively high dominance in terms of energetic demand when compared to its dominance by density. Psychropotes longicauda also had the strongest correlation 
between any taxon-specific density and $\mathrm{SC}_{\mathrm{E}}$ among the echinoderms at PAP $(R=0.76, P<0.001)$.

Respiration (TR) variation was highly correlated to the feeding-guild composition in terms of their energy demand $\left(\mathrm{FGC}_{\mathrm{E}}, R=0.86, P<0.001\right)$, where variation in surface deposit feeder (SDF) explained the greatest proportion of variation in $\mathrm{FGC}_{\mathrm{E}}$. While PAP trawl samples spanned four feeding guilds described by Iken et al. (2001), variation in $\mathrm{FGC}_{\mathrm{E}}$ was most related to SDF. The SDF guild made up $\sim 87 \%$ of the individuals, on average, followed in dominance by subsurface deposit feeders (SSDF; Fig. 5B), with Fig. 3 indicating guild assignments of the dominant fauna during relatively contrasting community compositions. Together, these two guilds made up an average of $95-99 \%$ of the echinoderms in the trawl collections for each of the sampling times, with suspension feeders and predator/ scavengers making up the remaining two guilds. The SDF respiration for the time series was more variable than that of the SSDF, which were relatively stable. However, the ratio of SDF to SSDF was not directly correlated to TR.

Covariances between pairwise taxon-specific energy demand over time were also about $1 / 2$ negative in sign (CD). Like Sta. M, there was also a significant negative correlation between mean individual respiration and total density $\left(\mathrm{ZSD}_{1}\right.$ hypothesis; $F=81.5, P<0.001$; Fig. 4 ), with higher evenness positively related to mean individual respiration rate $\left(r_{\mathrm{S}}=0.80, P<0.001\right)$. At PAP, TR was not found to increase relative to preceding POC flux by cross correlation analysis $\left(\mathrm{ZSD}_{2}\right.$ and $\mathrm{ZSD}_{3}$ hypotheses), as was done with Sta. M data, but this result could be related to the lower temporal resolution in data for PAP. Direct comparisons of POC flux quantity inputs (food supply) to TR (food demand) at PAP were not possible because of the known fishing efficiency issue with the otter trawl system.

\section{DisCuSSION}

Total respiration (TR) of the echinoderm assemblage was related to community indicators, with biomassbased indicators at both sites being more correlated to TR than density indicators in most cases (CCS hypothesis; Fig. 2, Table 1). Changes in distribution shape are evident in the rank abundance distributions (RADs; Fig. 3), but also the ranks of the top 10 dominant taxa over time with some taxa changing across ten or more ranks. Changes in taxon rank between density, biomass, and respiration RADs were driven, in part, by the fact that smaller fauna have higher massspecific respiration rates than larger fauna. As a result, the apparent dominance of a particular species in terms of density and/or biomass did not always translate to that species being dominant in terms of resource use (respiration).

Compensatory dynamics in terms of $>50 \%$ negative covariances were not found, even in terms of TR (CD hypothesis). Compensation in terms of zero-sum dy- namics was, however, observed at both sites with links to evenness $\left(\mathrm{ZSD}_{1}\right.$ hypothesis; Fig. 4.). Here, when fewer individuals were present, there tended to be higher mean individual respiration rates at both sites. Differences between sites in density and mean individual respiration relate to the different sampling tools as discussed in the methods. Zero-sum dynamics have also been found in communities of desert rodents and in a tropical forest community (White et al. 2004, Ernest et al. 2008, 2009).

At Sta. M, where links between food supply and community dynamics are best understood, we found evidence of the interplay between zero-sum compensation and the nonsteady state forcing of the system by changes in food supply. TR was correlated to POC flux (ZSD 2 hypothesis), and POC flux appeared to modulate zero-sum relationships between mean individual respiration rate and total density $\left(\mathrm{ZSD}_{3}\right.$ hypothesis). We found that, although there were straightforward metabolism-based zero-sum compensation dynamics like those evident in Fig. 4, there was also a correlation of POC flux with the residual variation in density found in Fig. 4A. Thus, as the density deviates from that expected by zero-sum compensation, food supply can explain some of this deviation in terms of more food supply relating to positive density residuals (Fig. 1).

Energetic theories of community structuring alone are not sufficient to explain the multimodal nature of the body size energy distribution at Sta. M (MMD hypothesis; Fig. 6). POC flux variation can be differentiated into temporal variance, as well as composition in terms of pigments, lipids, and other nutrients. Both quantity and quality of food supply to the benthos vary over time. This temporal variation in a common set of resources to a community of differentially responding fauna likely provides the mechanism by which the abyssal echinoderms have exhibited substantial switches in rank abundance (e.g., FitzGeorge-Balfour et al. 2010). The habitat and its scale may also lend advantage to fauna of particular size classes (Ernest 2005). It will be informative to continue examination of suitable data sets for MMD patterns, particularly where there are data that span larger size ranges and assemblage types. However, care must be taken in considering potential biases from sampling gear (Bett 2013).

The degree to which taxon-specific niche vs. sizerelated mechanisms drive community dynamics is unclear, but indications of both were evident. Within a food limited system, we observed compensatory dynamics, rank switches, and nonrandom links between TR and measures of biodiversity such as $\mathrm{SC}_{\mathrm{D}}$ and evenness. At PAP, where sampling included a broader range of feeding types, there were indications of correspondence between feeding-guild variation and respiration. Links to resource availability and assemblage changes in terms of density have been linked to environmental conditions at Station M (Ruhl 2008, Ruhl et al. 2008), and there is evidence that these differences translate to changes in reproductive potential (Wigham et al. 2003, Ruhl 2007, 


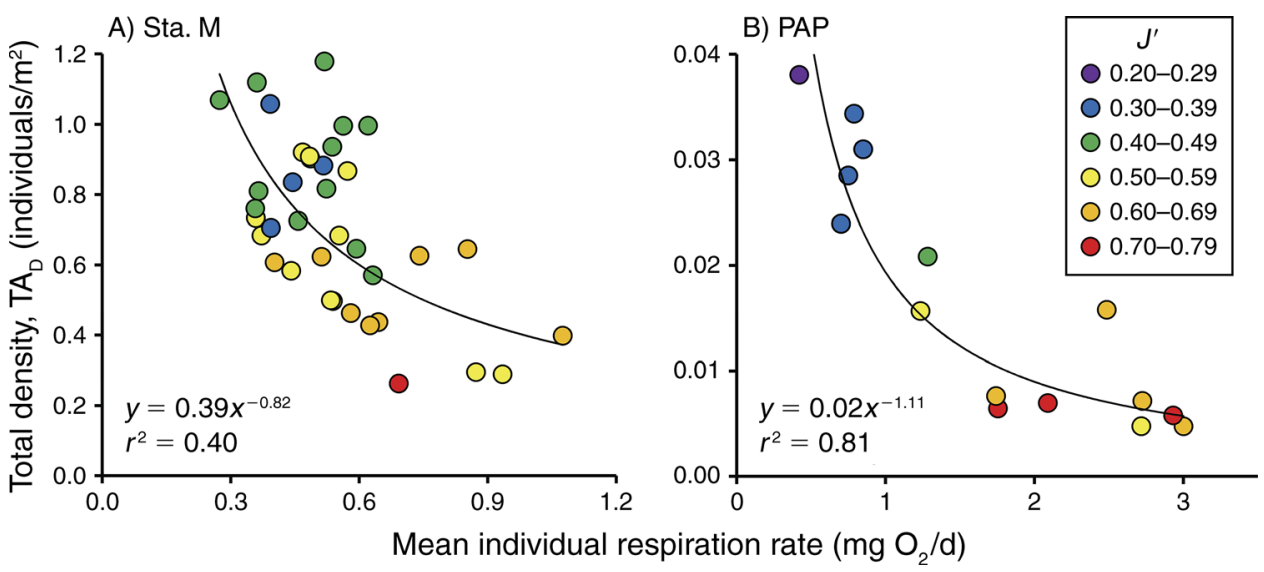

FIG. 4. Relationship between total density $\left(\mathrm{TA}_{\mathrm{D}}\right)$, mean individual respiration rates, and Pielou's index of evenness $\left(J^{\prime}\right)$ at $(\mathrm{A})$ Sta. M and (B) PAP. Points are monthly estimates. This figure provides data supporting hypothetical relationships presented in Fig. 1. The color in the points indicates corresponding evenness with the values provided in the legend to the right of panel $\mathrm{B}$.

FitzGeorge-Balfour et al. 2010). It is important to note, though, that swimming may provide another effective mechanism for abundance variation of some fauna at the study sites (Rogacheva et al. 2013). Several observed holothurians are capable of swimming, and thus, have potential ability for migration in terms of explaining observed variation, particularly Peniagone spp. and $A$. rosea, but the effectiveness of swimming as a migration mechanism is unknown.

The similarities in TR variation at both Sta. M and PAP suggest substantial variation in assemblage-related carbon cycle processes, at least on site specific and perhaps larger scales. The results from Sta. M suggest that food supply drives variation in respiration dynamics, in part. The results from Sta. $M$ also suggest a modest increase in shortfall between the supply and demand of incoming POC flux, as estimates now include data from the echinoderm assemblage. Because the efficiency with which POC is assimilated into tissue is generally thought to be proportional to respiration for these taxa (e.g., van Oevelen et al. 2012), the rates of secondary production from these assemblages likely have similar variation, as would the rates of remineral- ization. Benthic echinoderms have been estimated to contribute to a substantial portion of inorganic $\mathrm{C}$ production globally (up to about one-quarter that of pelagic inorganic C production; Lebrato et al. 2010). Even though the echinoderm production rates peak at shallower depths than those studied here, our results suggest the possibility of substantial temporal variation in those rates, which would likely apply to any area experiencing similar climate-driven variation.

Total respiration rates at PAP have notable similarity to estimates from an inverse model study. Van Oevelen et al. (2012) estimated SDF and SSDF respiration as part of a comprehensive inverse model budgeting of carbon stocks and flows at PAP. Both our study and the model study used the trawl sampling as inputs to the estimates, but the linear inverse model approach estimates these flows through balancing a series of equality and inequality equations where some, but not all flows are known a priori, whereas the estimates presented here are relatively empirical. For the period September 1996 to October 1998, the SDF respiration values measured here were $\sim 43 \%$ less than those based on inverse methods for that period.
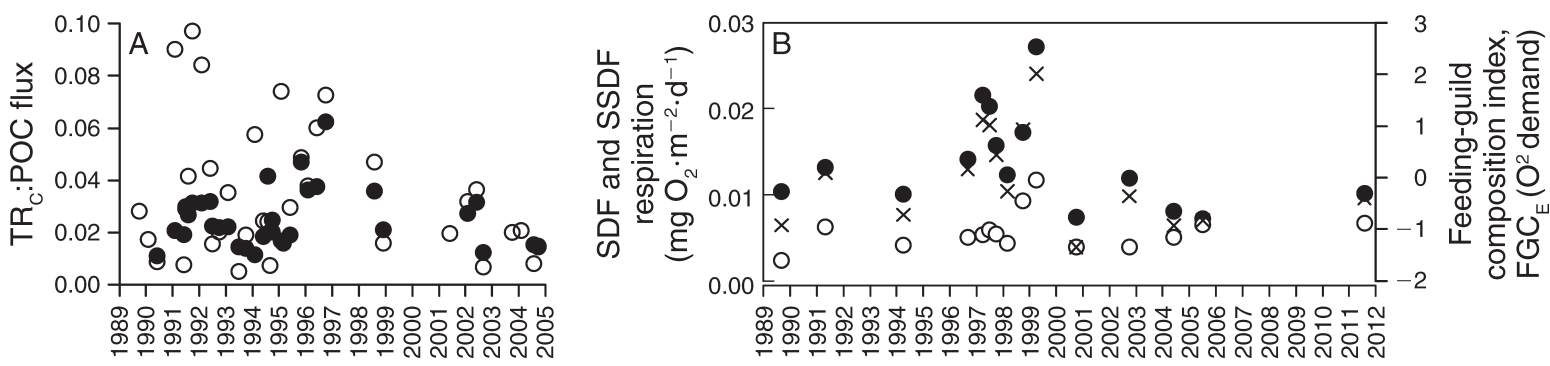

FIG. 5. Indicators of ecosystem function variation, including (A) Sta. M time series of monthly ratio between total echinoderm assemblage respiration in terms of respired $\mathrm{C}\left(\mathrm{TR}_{\mathrm{C}}\right)$ and mean particulate organic carbon (POC) food supplies both for synoptic fluxes (open circles; $\mathrm{TR}_{\mathrm{C}}$ :POC flux) and for the mean of the 12 months leading up to and including the monthly total respiration (TR) value (solid circles); and (B) monthly energetic demand estimates for PAP surface deposit feeders (solid circles; SDF) and subsurface deposit feeders (open circles; SSDF), as well as an index of feeding-guild composition over time based on energetic respiratory demand $\left(\times\right.$ 's; $\left.\mathrm{FGC}_{\mathrm{E}}\right)$. 


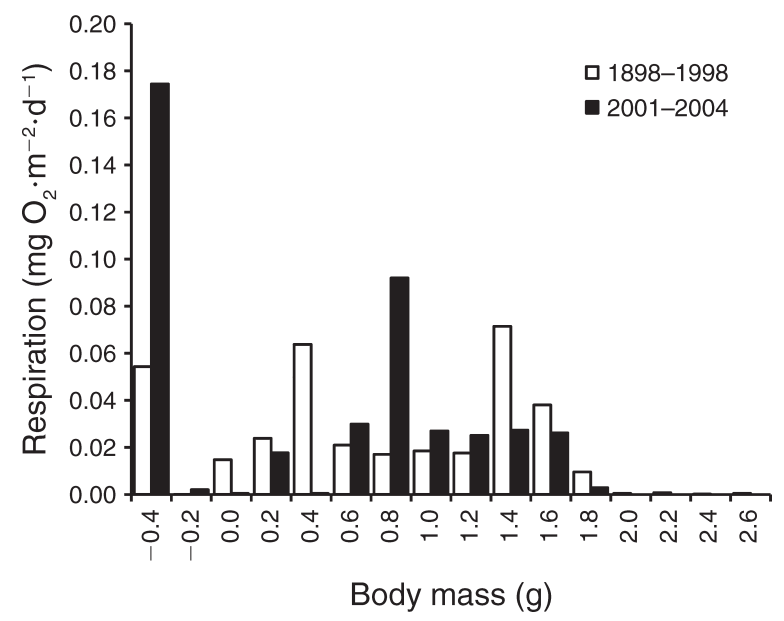

FIG. 6. Multimodal distributions of total respiration rates in 0.2-log unit size classes at Sta. M for the two periods with the most different species composition. The total respiration is corrected for the number of months with data for each period $(n$ $=29$ for 1989-1998, $n=8$ for 2001-2004). This figure illustrates that the assemblage does not have a uniform body size energy distribution.

The methods here provide the best available estimates for resource use of the studied fauna, which include empirical class-specific rates that do not rely on a priori allometric scaling relationships. A key limitation should be noted, though. The way we were able to apply sizespecific respiration rates to density and body size data over time did not allow for the fact that there could be variations in individual size-specific respiration over time within each taxon. During periods of higher fluxes, when activity is known to be higher from time lapse photography (Bett et al. 2001, Vardaro et al. 2009), individuals may have elevated respiration rates not accounted for here. Such changes in individual respiration in response to food input would likely increase correlation between POC flux and respiration fundamentally. However, increased respiration related to activity may also shorten the observed time lag in correlations between POC flux and respiration. Or it might introduce a multi-peaked distribution where a correlation with little or no time lag might be associated with individual metabolic change and longer term lagged correlation such as the one found here, which is driven by density and mass variations in the community.

The significant correlations found here have important unexplained variation; for example, between TR and POC flux. Higher resolution data sets with greater statistical power to discern food quantity and quality, as well as demand, will likely be needed to make progress in explaining a greater portion of variation (e.g., Sherman and Smith 2009). Further consideration of lateral flux of carbon, the flux of larger detrital aggregates and carrion, irregularly pulsed POC flux delivery contributing to a "food bank," is also warranted in helping to constrain food supply estimates, as well as the local production of biomass via background microbial chemosynthesis (Robison et al. 2005, Smith et al. 2006, Company et al. 2008, Drazen et al. 2012).

The extensive changes in respiration, resource use, remineralization, and community structure and composition meet specific assumptions of climate-driven community variation via niche-based and energetic abundance mechanisms. Climatic variations such as El Niño or the North Atlantic Oscillation can relate to ocean circulation, surface production, POC fluxes, and ultimately, deep-sea assemblages (reviewed in Smith et al. 2009). The observed changes in rank abundance of the studied assemblage appear to be related to the availability of a multivariate niche space that includes quantity and quality of food supplies. Moreover, the quantitative relationships identified between respiration and feeding guild have quantitative links to each other, providing evidence that multiple functional changes can be tied to basic changes in resources. If projected changes in ocean productivity occur (e.g., Steinacher et al. 2010), we expect that such changes would translate through to pervasive changes in benthic community structure and function.

As presented here, more long-term synoptic studies of the dynamics of resource availability, taxon-specific resource use, and ecosystem function over wider ranges of body size and taxa could help reconcile size- and energy-based theories of community structuring with niche theories (Isaac et al. 2013), as well as resolve imbalances in biogeochemical dynamics. An improved understanding of these relationships has implications not only for understanding climate-related impacts on the seafloor and other ecosystems, but also for disentangling climate from other forcing factors such as natural resource extraction.

\section{ACKNOWLEDgments}

Work at PAP has been supported in part by the European projects HERMES (Hotspot Ecosystem Research on the Margins of European Seas) and HERMIONE (Hotspot Ecosystem Research and Man's Impacts on European Seas), the EuroSITES open ocean observatory network, and the UK Natural Environment Research Council (NERC) Research Project Oceans 2025. Funding for work at Sta. M has been supported by the National Science Foundation and the David and Lucile Packard Foundation. Work from Sta. M contributes to the CCE-LTER (California Current Ecosystem Long-Term Ecology Research) program funded by the U.S. National Science Foundation. Thanks to Craig McClain for insightful discussions on macroecology, as well as thoughtful comments from the editor and anonymous reviewers, all of which benefited the manuscript. This work would not be possible without the efforts of a great number of seagoing crew and technical support and research staff who contributed to collecting this data since 1989 including Jacob Ellena, Roberta Baldwin, Ben Boorman, and many others. Identification and curation of collected specimens was made possible in part by, the Scripps Institution of Oceanography Benthic Invertebrate Collection, the Smithsonian Institution, and the Discovery Collections, a joint effort of the National Oceanography Centre and Natural History Museum, London. 


\section{Literature Cited}

Ambrose, W. G., Jr., L. M. Clough, P. R. Tilney, and L. Beer2001. Role of echinoderms in benthic remineralization in the Chukchi Sea. Marine Biology 139:937-949.

Baldwin, R. J., R. C. Glatts, and K. L. Smith, Jr. 1998. Particulate matter fluxes into the benthic boundary layer at a long time-series station in the abyssal NE Pacific: Composition and fluxes. Deep-Sea Research II 45:643-666.

Bett, B. J. 2013. Characteristic benthic size spectra: potential sampling artefacts. Marine Ecology Progress Series 487:1-6.

Bett, B. J., M. G. Malzone. B. E. Narayanaswamy, and B. D. Wigham. 2001. Temporal variability in phytodetritus and megabenthic activity at the seabed in the deep northeast Atlantic. Progress in Oceanography 50:349-368.

Billett, D. S. M., B. J. Bett, W. D. K. Reid, B. Boorman, and I.G. Priede. 2010. Long-term change in the abyssal NE Atlantic: The 'Amperima Event' revisited. Deep-Sea Research II 57:1406-1417.

Billett, D. S. M., B. J. Bett, A. L. Rice, M. H. Thurston, J. Galeron, M. Sibuet, and G. A. Wolff. 2001. Long-term change in the megabenthos of the Porcupine Abyssal Plain (NE Atlantic). Progress in Oceanography 50:325-348.

Clarke, K. R. 1993. Non-parametric multivariate analyses of changes in community structure. Australian Journal of Ecology 18:117-143.

Company, J. B., P. Puig, F. Sardà, A. Palanques, M. Latasa, and R. Scharek. 2008. Climate influence on deep sea populations. PLoS ONE 3:e1431.

Drazen, J. C., D. M. Bailey, H. A. Ruhl, and K. L. Smith, Jr. 2012. The role of carrion supply in the abundance of deepwater fish off California. PLoS ONE 7:e49332.

Ernest, S. K. M. 2005. Body size, energy use, and community structure of small mammals. Ecology 86:1407-1413.

Ernest, S. K. M., and J. H. Brown. 2001. Homeostasis and compensation: the role of species and resources in ecosystem stability. Ecology 82:2118-2132.

Ernest, S. K. M., J. H. Brown, K. M. Thibault, E. P. White, and J. R. Goheen. 2008. Zero sum, the niche, and metacommunities: long-term dynamics of community assembly. American Naturalist 172:E257-E269.

Ernest, S. K. M., E. P. White, and J. H. Brown. 2009. Changes in a tropical forest support metabolic zero-sum dynamics. Ecology Letters 12:507-515.

FitzGeorge-Balfour, T., et al. 2010. Phytopigments as biomarkers of selectivity in abyssal holothurians, interspecific differences in response to a changing food supply. Deep-Sea Research II 57:1418-1428.

Frölicher, T. L., F. Joos, G. K. Plattner, M. Steinacher, and S. C. Doney. 2009. Natural variability and anthropogenic trends in oceanic oxygen in a coupled carbon cycle-climate model ensemble. Global Biogeochemical Cycles 23:GB1003.

Gehlen, M., et al. 2007. The fate of pelagic $\mathrm{CaCO}_{3}$ production in a high $\mathrm{CO}_{2}$ ocean: a model study. Biogeosciences 4:505519.

Glover, A. G., et al. 2010. Temporal change in deep-sea benthic ecosystems: a review of the evidence from recent time-series studies. Advances in Marine Biology 58:1-98.

Grassle, J. F., H. L. Sanders, R. R. Hessler, G. T. Rowe, and T. McLellan. 1975. Pattern and zonation: a study of the bathyal megafauna using the research submersible Alvin. Deep-Sea Research 22:457-481.

Houlahan, J. E., et al. 2007. Compensatory dynamics are rare in natural ecological communities. Proceedings of the National Academy of Sciences USA 104:3273-3277.

Hubbell, S. P. 2001. The unified neutral theory of biodiversity and biogeography. Princeton University Press, Princeton, New Jersey, USA.

Hughes, S. J. M., et al. 2011. Deep-sea echinoderm oxygen consumption rates and an interclass comparison of metabolic rates in Asteroidea, Crinoidea, Echinoidea, Holothuroidea and Ophiuroidea. Journal of Experimental Biology 214: 2512-2521.

Iken, K., T. Brey, U. Wand, I. Voigt, and P. Junghans. 2001. Food web structure of the benthic community at Porcupine Abyssal Plain (N. Atlantic): a stable isotope analysis. Progress in Oceanography 50:383-405.

Isaac, N. J. B., D. Storch, and C. Carbone. 2013. The paradox of energy equivalence Global Ecology and Biogeography. Global Ecology and Biogeography 22:1-5.

Keeling, R. F., A. Körtzinger, and N. Gruber. 2010. Ocean deoxygenation in a warming world. Annual Review of Marine Science 2:199-229.

Lampitt, R. S., I. Salter, B. A. de Cuevas, S. Hartman, K. E. Larkin, and C. A. Pebody. 2010. Long-term variability of downward particle flux in the deep northeast Atlantic: Causes and trends. Deep-Sea Research II 57:1346-1361.

Lebrato, M., et al. 2010. Global contribution of echinoderms to the marine carbon cycle: $\mathrm{CaCO}_{3}$ budget and benthic compartments. Ecological Monographs 80:441-467.

MacArthur, R. H. 1957. On the relative abundance of bird species. Proceedings of the National Academy of Sciences USA 43:293-295.

Merrett, N. R., and N. B. Marshall. 1981. Observations on the ecology of deep-sea bottom-living fishes collected off northwest Africa $\left(08^{\circ}-27^{\circ} \mathrm{N}\right)$. Progress in Oceanography 9: 185-244.

Moeseneder, M. M., K. L. Smith, Jr., H. A. Ruhl, D. O. B. Jones, U. Witte, and J. I. Prosser. 2012. Temporal and depthrelated differences in prokaryotic communities in abyssal sediments associated with particulate organic carbon flux. Deep-Sea Research I 70:26-35.

Motomura, I. 1932. On the statistical treatment of communities. Zoological Magazine, Tokyo 44:379-383.

Orr, J. C., et al. 2005. Anthropogenic ocean acidification over the twenty-first century and its impact on calcifying organisms. Nature 437:681-686.

Piepenburg, D., and M. K. Schmid. 1996. Distribution, abundance, biomass, and mineralization potential of the epibenthic megafauna of the Northeast Greenland shelf. Marine Biology 125:321-332.

Robison, B. H., K. R. Reisnebichler, and R. E. Sherlock. 2005. Giant larvacean houses: Rapid carbon transport to the deep sea floor. Science 308:1609-1611.

Rogacheva, A., A. Gebruk, and C. H. S. Alt. 2013. Holothuroidea of the Charlie Gibbs Fracture Zone area, northern Mid-Atlantic Ridge. Marine Biology Research 9: 587-623.

Rowe, G. T., et al. 2008. Comparative biomass structure and estimated carbon flow in food webs in the deep Gulf of Mexico. Deep-Sea Research II 55:2699-2711.

Ruhl, H. A. 2007. Abundance and size distribution dynamics of abyssal epibenthic megafauna in the northeast Pacific. Ecology 88:1250-1262.

Ruhl, H. A. 2008. Community change in the variable resource habitat of the abyssal northeast Pacific. Ecology 89:9911000 .

Ruhl, H. A., J. A. Ellena, and K. L. Smith, Jr. 2008. Connections between climate, food limitation, and carbon cycling in abyssal sediment communities. Proceedings of the National Academy of Sciences USA 105:17006-17011.

Ruhl, H. A., et al. 2011. Societal need for improved understanding of climate change, anthropogenic impacts, and geo-hazard warning drive development of ocean observatories in European Seas. Progress in Oceanography 91:1-33.

Sherman, A. D., and K. L. Smith, Jr. 2009. Deep-sea benthic boundary layer communities and food supply: A long-term monitoring strategy. Deep-Sea Research II 56:1754-1762.

Smith, C. R., S. Mincks, and D. J. DeMaster. 2006. A synthesis of bentho-pelagic coupling on the Antarctic shelf: Food 
banks, ecosystem inertia and global climate. Deep-Sea Research II 53:875-894.

Smith, K. L., Jr. 1983. Metabolism of two dominant epibenthic echinoderms measured at bathyal depths in the SantaCatalina Basin. Marine Biology 72:249-256.

Smith, K. L., Jr. 1974. Oxygen demands of San Diego Trough sediments: an in situ study. Limnology and Oceanography 19: 939-944.

Smith, K. L., Jr., H. A. Ruhl, B. J. Bett, D. S. M. Billett, R. S. Lampitt, and R. S. Kaufmann. 2009. Climate and deep-sea communities. Proceedings of the National Academy of Sciences USA 46:19211-19218.

Smith, K. L., Jr., H. A. Ruhl, R. S. Kaufmann, and M. Kahru. 2008. Tracing abyssal food supply back to upper-ocean processes over a 17 -year time series in the northeast Pacific. Limnology and Oceanography 53:2655-2667.

Steinacher, M., et al. 2010. Projected 21st century decrease in marine productivity: a multi-model analysis. Biogeosciences 7:979-1005.

Sugihara, G., L.-F. Bersier, T. R. S. Southwood, L. Pimm, and R. M. May. 2003. Predicted correspondence between species abundances and dendrograms of niche similarities. Proceed- ings of the National Academy of Sciences USA 100:52465251.

Thibault, K. M., E. P. White, and S. K. M. Ernest. 2004. Temporal dynamics in the structure and composition of a desert rodent community. Ecology 85:2649-2655.

van Oevelen, D., K. Soetaert, and C. Heip. 2012. Carbon flows in the benthic food web of the Porcupine Abyssal Plain: The (un)importance of labile detritus in supporting microbial and faunal carbon demands. Limnology and Oceanography 57: 645-664.

Vardaro, M. F., H. A. Ruhl, and K. L. Smith, Jr. 2009. Climate variation, carbon flux and bioturbation in the abyssal North Pacific. Limnology and Oceanography 54:2081-2088.

White, E. P., S. K. M. Ernest, and K. M. Thibault. 2004. Tradeoffs in community properties through time in a desert rodent community. American Naturalist 164:670-676.

Whittaker, R. H. 1965. Dominance and diversity in land plant communities. Science 147:250-260.

Wigham, B. D., P. A. Tyler, and D. S. M. Billett. 2003. Reproductive biology of the abyssal holothurian Amperima rosea: an opportunistic response to variable flux in surface derived organic matter? Journal of the Marine Biological Association of the United Kingdom 3:175-188. 